\title{
No differences in clinical outcomes between fixed- and mobile- bearing computer-assisted total knee arthroplasties and no correlations between navigation data and clinical scores
}

\author{
Carlos J. Marques · Sandra Daniel • \\ Anusch Sufi-Siavach $\cdot$ Frank Lampe
}

Received: 14 February 2014 / Accepted: 4 June 2014/Published online: 15 June 2014

(C) The Author(s) 2014. This article is published with open access at Springerlink.com

\begin{abstract}
Purpose The theoretical advantages of mobile-bearing (MB) designs over the conventional fixed bearings (FBs) for total knee arthroplasty (TKA) have not been proved yet through clinical studies. The aim of the study was to test whether the MB design has advantages in terms of better clinical outcomes when compared to FB. Furthermore, the relationships between intra-operative obtained implant positioning data and the clinical scores were analysed.

Methods A total of 99 patients were randomized into the FB or the MB group. All patients received the same posterior cruciate retaining implants and were operated with the use of a computer-assisted navigation system. The clinical outcomes of both groups were compared preoperatively, at 1 year, and at a mean follow-up time of 4 years after surgery.

Results The MB implants showed no advantages over the FB when comparing the Knee Society Scores, the Oxford
\end{abstract}

\section{J. Marques $(\bowtie) \cdot$ F. Lampe}

Research Center of the Orthopedic and Joint Replacement Department, Schoen Klinik Hamburg Eilbek, Dehnhaide 120,

22081 Hamburg, Germany

e-mail: cmarques@schoen-kliniken.de

F. Lampe

e-mail: flampe@schoen-kliniken.de

S. Daniel · A. Sufi-Siavach

Orthopedic and Joint Replacement Department, Schoen Klinik

Hamburg Eilbek, Dehnhaide 120, 22081 Hamburg, Germany

e-mail:sdaniel@schoen-kliniken.de

A. Sufi-Siavach

e-mail: asufi@schoen-kliniken.de

F. Lampe

Faculty of Life Sciences, Hamburg University of Applied

Sciences, Lohbrügger Kirchstraße 65, 21033 Hamburg, Germany
Score, the range of movement (ROM) and pain intensity of the patients in both groups at 1 and 4 years after surgery. There were no relationships between the computer navigation data and the clinical scores.

Conclusions In view of the 4-year results, there is no evidence to support the recommendation of one design over the other in terms of better clinical outcome scores, higher ROM or lower pain rates. Long-term follow-up results may be necessary, including survival rates. Further research comparing different TKA designs should also include standardized performance-based tests.

Level of evidence Prospective study (Randomized controlled trial with adequate statistical power to detect differences), Level I.

Keywords Mobile bearing - Fixed bearing - Total knee replacement · Computer-assisted surgery $\cdot$ Randomized controlled trial

\section{Introduction}

Patients submitted to total knee arthroplasty (TKA) experience a significant improvement in their health-related quality of life (HRQOL) already soon after surgery [2, 4, 8, 27]. The HRQOL improvements observed at short term maintain over the years $[8,19,26]$.

In observational studies, the long-term survival rates reported after TKA are high and range from $90 \%$ at 15 years [30] to $82 \%$ at 22 years [32]. Despite high survival rates, causes of revisions like short-term anterior knee pain, aseptic loosening of the tibia component and wear of the polyethylene (PE) insert remained unsolved. Attempting to solve these problems, the mobile-bearing (MB) designs were introduced. MB TKA designs were claimed 
to reduce the risk of aseptic loosening by minimizing the stress transmitted to the prothesis-bone interface, to reduce the wear of the PE insert by increasing the implant conformity [34, 41], to increase the overall range of motion by allowing the femur to roll back during flexion and to rotate during extension and to reduce the anterior knee pain rates [40].

These theoretical advantages of MB over fixed bearing (FB) designs could not be demonstrated by recently published studies [5, 9, 28]. In a systematic review and metaregression including 41 studies comparing $\mathrm{MB}$ versus $\mathrm{FB}$ for TKA, the authors found no clinically relevant differences in terms of clinical outcome scores, revision rates and patient-reported outcome measures [37].

To minimize bias that may emerge with the use of different implant types, different surgical techniques and postoperative rehabilitation programs, a randomized doubleblind clinical trial was designed. All surgeries were performed with a computer-assisted navigation system by two experienced surgeons, using always the same cruciate retaining implant types. The only varying parameter was the mobility of the PE inlay. The aim of the study was to compare the effects of fixed versus MB in TKA on clinically relevant outcomes. The Knee Society Score (KSS) [16] of both groups was compared as primary end point. The Oxford Score (OXF) [11], the range of movement (ROM-passive flexion) and two sub-items of the KSS (KSS-Pain and KSS-Stairs) were also compared between the groups as secondary outcomes. A secondary purpose of this study was to test for relationships between the intraoperative-obtained computer navigation data and the clinical scores. The following hypotheses were formulated: (1) there would be no differences between the MB and FB groups across the follow-up assessments; and that (2) there would be no significant relationships between the navigation data and the clinical scores.

\section{Materials and methods}

To study potential effects of the implant type on clinical relevant outcomes, a double-blind randomized controlled trial was designed. From April 2004 until June 2007, 99 patients (100 knees) scheduled for primary bicondylar, posterior cruciate retaining TKA at the Schoen Klinik Hamburg Eilbek, Germany, were informed about the study and agreed to participate. Before participating, all patients were required to read and sign an informed consent form.

If the patients met the inclusion criteria (clinical and radiological signs of osteoarthritis of the knee with failed non-operative treatment; no indication for a uni-compartmental implant or joint-preserving osteotomies; age ranging from 40 to 90 years; American society of anaesthesiologists pre-operative classification grade 1-3; no deformity larger than 20 varus or $15^{\circ}$ valgus; no previous bone surgery to the index knee; no previous total joint replacement at the index leg; no post-operative infection of the index knee or thrombosis within the follow-up period), they were randomly assigned either to the FB or the MB group. The randomization was made with concealed envelopes labelled with random numbers. Neither the patients nor the assessor knew in which group the patient was allocated (double-blind). Only the surgeon got the information inside the concealed envelope on which kind of implant the patient should get.

At each examination the OXF, the KSS and ROM of the indexed knee were assessed by a trained physician. The patients received standardized instructions and were required to answer the OXF questionnaire on their own. The KSS questionnaire was answered with support of the physician. German translations of both questionnaires were used.

Range of movement was assessed with an analogue goniometer with the patient lying in the supine position as described in the literature [25].

All patients were operated by one of two senior surgeons with the use of an imageless computer navigation system (Orthopilot TKA 4.2, BBraun Aesculap, Tuttlingen, Germany) [15], allowing the acquisition of the following intraoperative implant positioning data: femoral angle coronal (FAC); femoral angle sagittal (FAS); tibial angle coronal (TAC); tibial angle sagittal (TAS).

In the FB group, the implant used (Columbus CR, BBraun Aesculap, Tuttlingen, Germany) had a PE inlay rigidly fixed to the tibial tray. In the $\mathrm{MB}$ version of the implant (Columbus RP, BBraun Aesculap, Tuttlingen, Germany), the PE inlay rotates around a cylindrical post within a range of $\pm 10^{\circ}$ limited by a second post placed interiorly on the surface of the tray. The femoral components were identical in both groups. All components were cemented, and no patellar components were implanted.

After surgery, all patients followed a standard rehabilitation protocol, including self-controlled epidural analgesia with ropivacaine, non-steroidal oral analgesia and antithrombotics. Physiotherapy started one day after surgery.

During the patient recruitment period, 52 patients were randomly allocated in the $\mathrm{FB}$ and 48 in the MB group. The mean age of the patients by entrance in the study was $68.9 \pm 8.4$ and $69.4 \pm 7.1$ years for the FB and MB groups, respectively. The mean difference was statistically not significant (n.s.) when comparing the groups. The mean body mass index (BMI) of both groups was also statistically equal (n.s.). For further demographic data, see Table 1.

The patients were followed up at 12 months and at a mean follow-up time of 4 years post-surgery. At 1 year, there was no patient lost to follow-up in the FB group and 
Table 1 Demographic data of the sample by the time of entry in the study

\begin{tabular}{lllll}
\hline Variables & All & FB & MB & Mean diff. ( $p$ value) [95\% CI] \\
\hline Number of patients & $n=100$ & $n=52$ & $n=48$ & \\
Gender (F; M) & $74 \mathrm{~F} ; 26 \mathrm{M}$ & $39 \mathrm{~F} ; 13 \mathrm{M}$ & $34 \mathrm{~F} ; 14 \mathrm{M}$ & 0.4 (n.s.) \\
Age (years) & $69.1 \pm 7.8$ & $68.9 \pm 8.4$ & $69.4 \pm 7.1$ & $6.3(p=0.04)[-12.5 \text { to }-0.09]^{*}$ \\
Body weight $(\mathrm{kg})$ & $82.6 \pm 15.7$ & $79.6 \pm 13.8$ & $85.9 \pm 17$ & 1.6 (n.s.) \\
Body height $(\mathrm{cm})$ & $167.1 \pm 8.4$ & $166.4 \pm 8.7$ & $168 \pm 8$ & 1.6 (n.s.) \\
BMI $\left(\mathrm{kg} / \mathrm{m}^{2}\right)$ & $29.5 \pm 5.5$ & $28.7 \pm 4.9$ & $30.4 \pm 6$ & \\
\hline
\end{tabular}

Values are mean $\pm \mathrm{SD}$

$F B$ fixed bearing, $M B$ mobile bearing, $M$ male, $F$ female, n.s. non-significant

* Significant difference

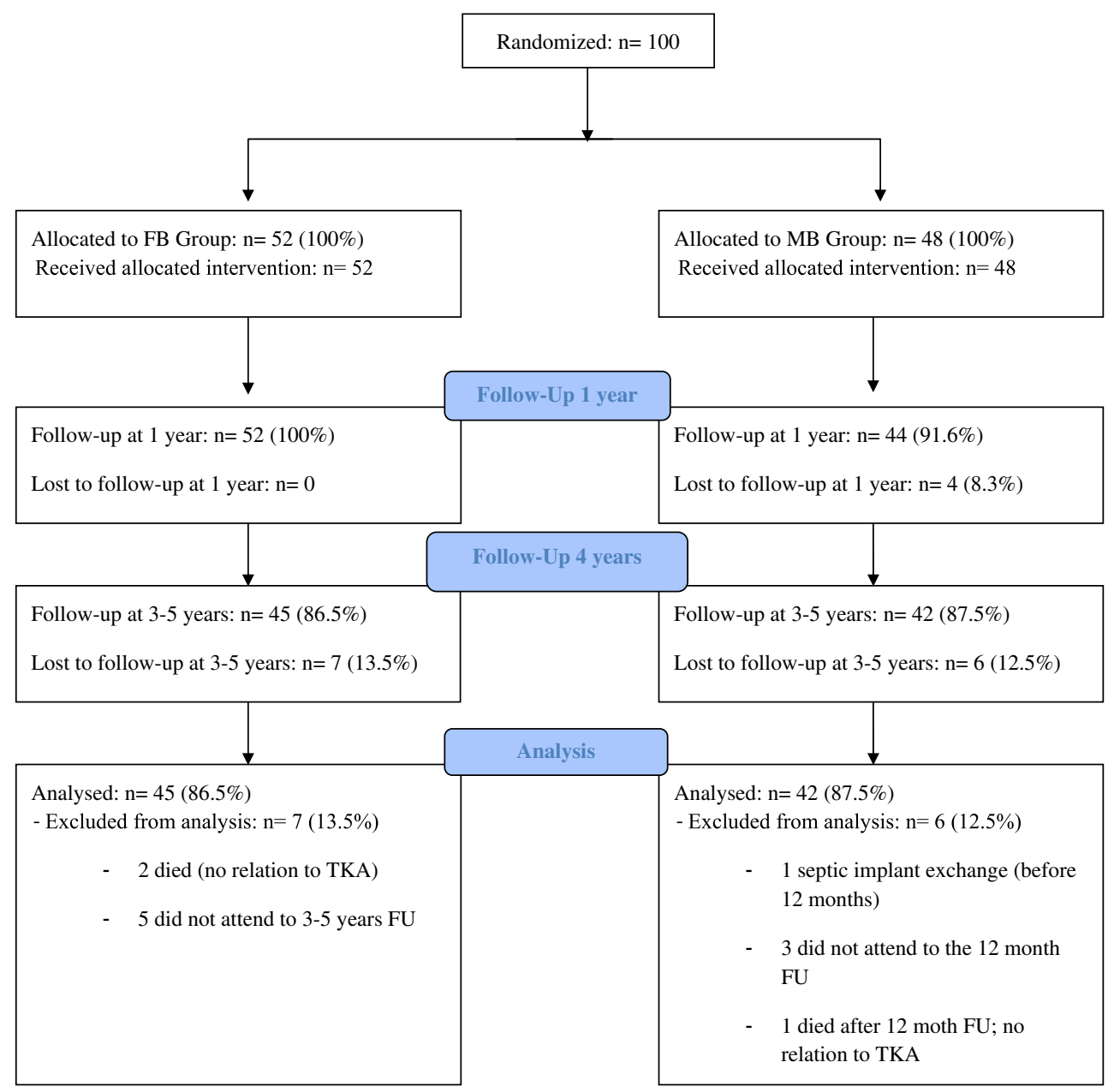

Fig. 1 Patient flow diagram according to the CONSORT statement. There is neither available data on the number of patients assessed nor on the number of patients excluded and their exclusion reasons

four patients dropped out in the MB group: one patient was excluded because of a septic implant exchange before 12 months and three did not attend the 12-month follow-up examination. Four years after surgery, there was a lost to follow-up rate of $13.5(n=7)$ and $12.5 \%(n=6)$ in the FB and MB groups, respectively. The reasons of lost to follow-up were neither related to surgery nor to the type of implant used and are exposed in the flow diagram (Fig. 1).

The Medical Ethics Commission of the Federal State of Hamburg approved the research proposal (File \#2226). The trial was registered under ClinicalTrials.gov (NCT00822640). 
The data of 87 patients (45 in the FB and 42 in the MB group) were included for analysis. The normal distribution of the variable data was confirmed with the KolmogorovSmirnov test. Independent variable data comparisons between the two groups at baseline were performed with a $t$ test for independent samples (Table 1$)$.

A mixed design ANOVA $(2 \times 3)$ for repeated measures was chosen to test for differences between the KSSFunction, KSS-Knee, OXFs and ROM (passive flexion) between the groups across the measurement times. The Greenhouser-Geisser correction was chosen when the sphericity assumption was not assumed. In cases where the $2 \times 3$ ANOVA revealed no significant interactions between the implant type (FB vs. $\mathrm{MB}$ ) and the repeated measure factor, and no significant main effects for the implant type, a one-way ANOVA was performed for the all sample to test for differences across the time. Post hoc multiple comparisons were made with paired $t$ tests with the Bonferroni adjustment of the alpha.

A nonparametric approach was chosen to analyse KSS sub-items "Pain" and "Stairs", since the values were not normal distributed. To compare the sub-items of both groups at each follow-up time, the Man-Whitney $U$ test was used. When no differences were found between the FB and MB groups at each point in time for each of the sub-items, both groups were collapsed and further analysis was made for the all sample. A Friedman's ANOVA was performed to test for differences between the scores at baseline, 1 year and at 4 years. Multiple comparisons were conducted between the paired follow-up times with Wilcoxon signed rank procedures with alpha set at $0.017(0.05 / 3$ tests $=0.017)$ to compensate for alpha inflation with multiple testing.

Pearson's product-moment correlation ( $r$ ) was run to determine the relationships between the intra-operative obtained navigation data (implant positioning data), leg alignment data and the clinical scores.

Power analysis was performed based on the KSS values reported in the literature [10, 29]. An estimated effect size of $d=0.67$ with the alpha set at 0.05 and beta set at 0.15 revealed a sample size of 42 patients per group. The sample size was raised up to 50 patients per group, accounting for $20 \%$ lost to follow-up.

All statistical tests were carried out with the use of the IBM SPSS software version 21 for Mac. For all statistical tests, except for multiple comparisons, the 0.05 level of probability was accepted as the criterion for statistical significance.

\section{Results}

Knee Society Score-Function scores were not equal when comparing both groups across time $(F=4.2 ; p=0.02)$.
Post hoc analysis revealed a ten points significant better KSS-Function result for the FB group at baseline $(p=0.009)$. There were neither significant mean KSSFunction differences between both groups at 1 nor at 4 years (Table 2). The mean KSS-Function improvements between pre-operatively and 1 year were $35.4 \pm 18.2$ and $45 \pm 21.1$ for the $\mathrm{FB}$ and $\mathrm{MB}$ groups, respectively. The mean difference was significant $(p=0.01)$, showing a significantly greater post-operative improvement for the patients in the MB group during the first post-surgery year. There was a significant main effect for the repeated measure factor $(p<0.001)$. KSS-Function improved significantly from baseline to 1 year $(p<0.001)$ and stabilized from 1 to 4 years (n.s.) in both groups.

Knee Society Score-Knee score differences between the groups across the measurement times were not significant (n.s.). Ignoring the implant type, there was a significant main effect for the repeated measure factor $(p<0.001)$. The mean KSS-Knee score improved significantly from baseline to 1 year $(p<0.001)$ and maintained between 1 and 4 years (n.s.).

Oxford Scores of both groups across the time were not significantly different. Ignoring the implant type, there was a significant effect for the repeated measure factor $(p<0.001)$. The OXF improved significantly for all patients between baseline and 1 year $(p<0.001)$ and remained stable between 1 year and the last follow-up.

Range of movement of both groups was not different from each other across the time (Table 3). Once again, ignoring whether the patients got a FB or a MB implant, there was an overall significant difference in ROM across the measurement times $(p<0.001)$. Pairwise comparisons shown that a $3.8 \%$ overall mean ROM increase between baseline and 1 year was statistically significant $(p=0.01)$. ROM remained stable between 1 and 4 years (n.s.).

The median of the sub-item KSS-Pain was the same in both groups across the follow-up times: zero (severe pain) at baseline and 50 (no pain) at 1 and 4 years. There was a significant difference between the mean KSS-Pain ranks $\left(x^{2}=156.9, p<0.001\right)$. The patients perceived a significant pain relieve from pre-operatively to 1 year $(Z=8.6$; $p<0.001)$. The pain relieve remained at 4 years $(Z=0.3$; n.s.) (Fig. 2a).

The median of the sub-item KSS-Stairs was equal for both groups across the time: 30 at baseline (up and down with rail) and 40 at 1 and 4 years (normal up, down with rail). There was a significant difference between the mean ranks $\left(x^{2}=107.3, p<0.001\right)$. Patient's ability to walk stairs improved significantly from pre-operatively to 1 year $(Z=7.6 ; p<0.001)$ and kept stable from 1 to 4 years ( $Z=0.8$; n.s.) (Fig. 2b).

Intra-operative obtained navigation data on implant positioning, and leg alignment data out of long leg X-rays 
Table 2 Data of the dependent variables across the measurement times

\begin{tabular}{|c|c|c|c|c|c|}
\hline & Group & Pre & 1 year & 4 years & Results \\
\hline KSS-Function & $\mathrm{FB}(n=45)$ & $\begin{array}{l}60(0-70) \\
53.7 \pm 16.8 \\
50(0-70) \\
42.9 \pm 21.4 \\
60(0-70) \\
48.5 \pm 19.8\end{array}$ & $\begin{array}{l}90(45-100) \\
89 \pm 13.2 \\
90(55-100) \\
88.1 \pm 11.5 \\
90(45-100) \\
88.5 \pm 12.4\end{array}$ & $\begin{array}{l}90(30-100) \\
85 \pm 16.9 \\
90(60-100) \\
85 \pm 13 \\
90(30-100) \\
85 \pm 15.1\end{array}$ & $\begin{array}{l}2 \times 3 \text { ANOVA results: }(1) \text { significant interaction } \\
\text { between implant type and time }(F=4.2 ; \\
p=0.02)^{*} \text {; post hoc significant mean KSS-F } \\
\text { difference between FB and MB pre- } \\
\text { operatively: } 10.3(p=0.009) \text { [2.6-18.0 }]^{*} ;(2) \\
\text { significant main effects for the factor time } \\
(F=235.9 ; p<0.001)^{*} ; \text { post hoc-FB: pre to } \\
1 \text { year: } 35.2(p<0.001)[-42.1 \text { to }-28.2]^{*} \\
1-4 \text { year: } 4.0 \text { (n.s.); MB: pre to } 1 \text { year: } 45.1 \\
(p<0.001)[-53.3 \text { to }-36.8]^{*} \\
1-4 \text { year: } 3.0 \text { (n.s.) }\end{array}$ \\
\hline KSS-Knee & FB & $\begin{array}{l}29(0-56) \\
29.5 \pm 10.8 \\
25.5(17-55) \\
29.4 \pm 9.6\end{array}$ & $\begin{array}{l}89(41-100) \\
86.9 \pm 12.4 \\
91.5(40-100) \\
88.1 \pm 11.9\end{array}$ & $\begin{array}{l}89(40-100) \\
85.1 \pm 13.5 \\
89.5(65-100) \\
87 \pm 9\end{array}$ & $\begin{array}{l}2 \times 3 \text { ANOVA results: no significant interaction } \\
\text { between implant type and time }(F=0.1 ; \text { n.s. }) \\
\text { significant main effects for the factor time } \\
(F=815.8 ; p<0.001)\end{array}$ \\
\hline & All & $\begin{array}{l}28(0-56) \\
29.4 \pm 10.2\end{array}$ & $\begin{array}{l}91(40-100) \\
87.5 \pm 12.1\end{array}$ & $\begin{array}{l}89(40-100) \\
86 \pm 11.5\end{array}$ & $\begin{array}{l}\text { Pre to } 1 \text { year: } 58(p<0.001)[-62.5 \text { to }-53.5]^{*} \\
1-4 \text { years: } 1.4 \text { (n.s.) }\end{array}$ \\
\hline Oxford Score & MB & $\begin{array}{l}39.5(22-55) \\
39.9 \pm 7 \\
42(31-53) \\
42.5 \pm 4.7\end{array}$ & $\begin{array}{l}17.5(12-52) \\
19.6 \pm 8.4 \\
18(12-43) \\
20.2 \pm 7.9\end{array}$ & $\begin{array}{l}16(12-52) \\
19.8 \pm 9.8 \\
16(12-44) \\
19.4 \pm 7.5\end{array}$ & $\begin{array}{l}2 \times 3 \text { ANOVA results: no significant interaction } \\
\text { between implant type and time }(F=1.5 ; \text { n.s. }) \text {; } \\
\text { significant main effects for the factor time } \\
(F=345 ; p<0.001)^{*}\end{array}$ \\
\hline & All & $\begin{array}{l}41(22-55) \\
41.2 \pm 6.1\end{array}$ & $\begin{array}{l}18(12-52) \\
19.9 \pm 8.1\end{array}$ & $\begin{array}{l}16(12-52) \\
19.6 \pm 8.7\end{array}$ & $\begin{array}{l}\text { Pre to } 1 \text { Y: } 21.3(p<0.001)[18.9-23.6]^{*} \\
1-4 \text { Y: } 0.3 \text { (n.s.) }\end{array}$ \\
\hline
\end{tabular}

Values are median (range) and mean \pm SD for the Knee Society Score (KSS) and Oxford Score

$M B$ mobile bearing, $F B$ fixed bearing; Pre pre-operatively, $Y$ Year(s), n.s. non-significant, $Y$ year(s)

* Significant difference

were similar in both groups without statistically significant differences (Table 4).

Pearson's product-moment correlations revealed a week positive relationship between the FAS and the maximal knee flexion at 1 year $(r=0.226 ; p<0.5)$. There were no significant relationships between the navigation data on implant positioning and the clinical scores (Table 5).

\section{Discussion}

The most important finding of the present study was the lack of results supporting the superiority of one design (FB or MB) over the other in terms of higher ROM, lower pain rates or better patient perceived functional scores. Interestingly, within the first year post-surgery the KSS-Score of the patients in the MB group had a significantly higher improvement rate, though with no differences between the groups neither at 1 nor at 4 years.

The theoretical advantages of MB designs over the conventional FB in TKA were not clinically demonstrated by the time this study was designed. In order to minimize possible influences of different surgical techniques,
Table 3 Data of the dependent variable ROM (passive flexion)

\begin{tabular}{llll}
\hline Group & Pre-operative & 1 year & 4 years \\
\hline ROM & & & \\
FB $(n=45)$ & $110.6 \pm 15.5$ & $112.8 \pm 13.3$ & $114.3 \pm 9.3$ \\
MB $(n=42)$ & $109.4 \pm 12.7$ & $115.7 \pm 11.1$ & $117.7 \pm 10.9$ \\
All $(n=87)$ & $110 \pm 14.2$ & $114.2 \pm 12.3$ & $115.9 \pm 10.2$ \\
Mean diff. & $4.2(p=0.01)[-7.9$ to - & 1.7 (n.s. $)$ \\
$(p$ value $)$ & $0.6]^{*}$ & $1.4 \%$ increase \\
{$[95 \%$ CI $]$} & $\begin{array}{c}3.8 \% \text { increase from baseline } \\
\text { from 1 to }\end{array}$ \\
Diff. rates $(\%)$ & to 1 year & 3-5 years \\
\hline
\end{tabular}

Values are mean $\pm \mathrm{SD}$ for range of movement (ROM-passive flexion)

$M B$ mobile bearing, $F B$ fixed bearing, n.s. non-significant

* Significant difference

prosthesis types, expectations of patients and assessors, and post-surgery rehabilitation protocols on the results, a double-blind randomized clinical trial was implemented. Despite dropout rates of 13.5 and $12.5 \%$ in the FB and MB groups, respectively, the sample sizes at 4-year follow-up were still within the preliminarily calculated size of 42 patients per group. 

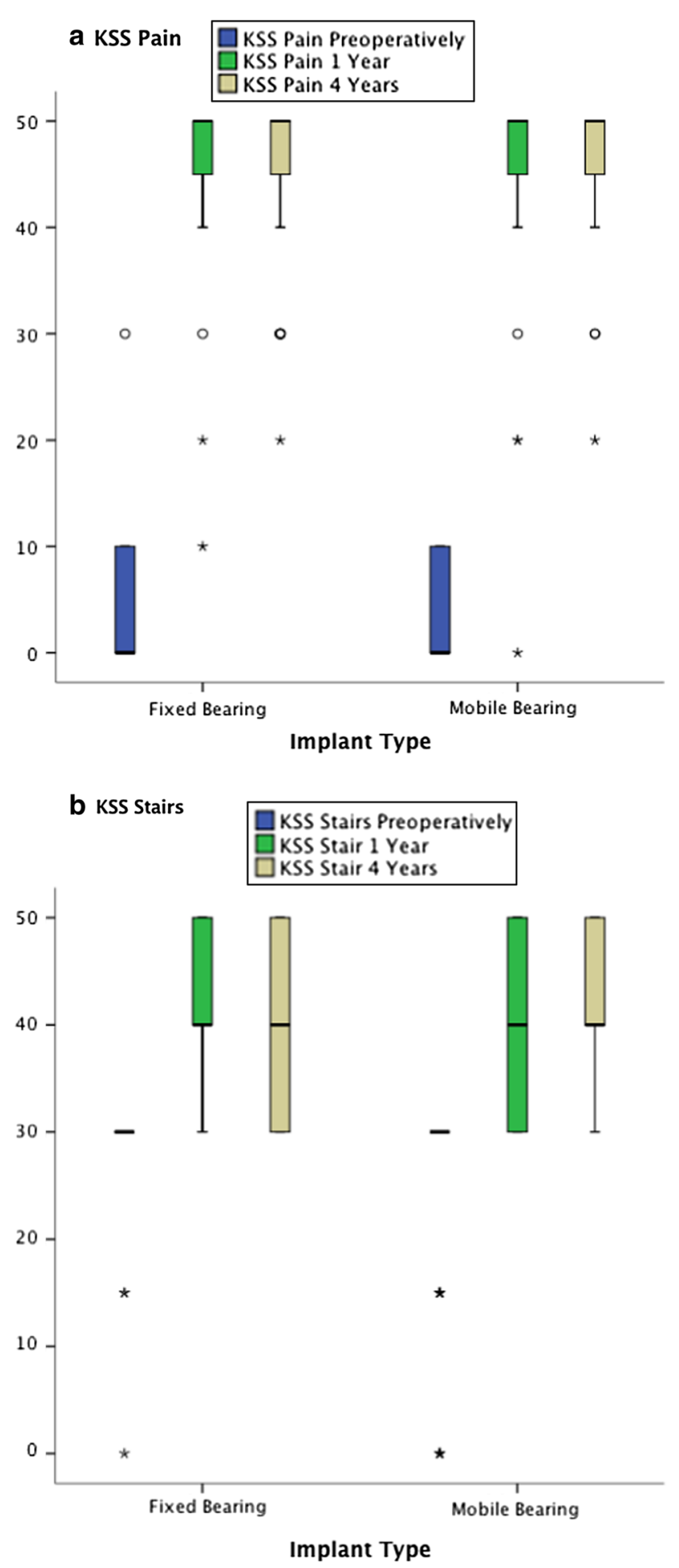

Fig. 2 a KSS-Pain for the FB and MB groups across the measurement times (pre-operatively and at 1 and 4 years). b KSS-Stairs for the FB and MB groups across the measurement times (pre-operatively and at 1 and 4 years)

Both groups (FB and $\mathrm{MB}$ ) were similar at baseline in regard to their demographic data, with exception of "body weight" ( $p=0.04)$ with no impact on mean BMI differences (n.s.). There were also no statistically significant differences when comparing the radiological leg alignment data of both groups pre-operatively (Table 4).

The prosthesis type can influence the clinical outcomes as proved in a recent study by Mugnai et al. [24]. In their study, it was demonstrated that the bearing geometry and the kinematic pattern of different prosthetic designs have an effect on clinical outcomes. In the present study, all patients received the same femoral and tibial prosthetic component types and both prosthesis types were posterior cruciate ligament retaining; the only difference between the groups was the mobility of the PE bearing. In addition, all components were cemented. In a recent study [17] on the effects of cemented versus hybrid MB TKA implantations, there were no differences found in terms of revision rates, mortality, alignment deviations or evidence of loosening, when comparing both groups. These results challenge the theoretical assumption that a hybrid fixation (cement-less femoral component) in a MB knee system might increase the rate of loosening of the femoral component.

In a study by Roh et al. [31] comparing highly conforming PCL-retaining vs. PCL-sacrificing MB knees, there were kinematic differences between both procedures, however, with no consequences in terms of significant differences in ROM, functional scores or radiographic results. In the present study, all patients received a PCLretaining TKA, with no outcome differences when comparing both groups across the time. These results are congruent with the ones by Bailey and colleagues [3].

At baseline, the mean KSS-Function score of the patients in the MB group was ten points inferior $(p=0.009)$ in comparison with the FB group. Despite this significant difference, there were no longer differences when comparing the groups at 1 year, with both groups achieving exactly the same mean KSS-Function score at 4 years. The KSS-Function improvement rate within the first year was significantly greater in the MB group $(p=0.01)$.

The KSS-Knee and Oxford Knee scores of both groups across the time were not significantly different from each other. These results reinforce the ones of recently published randomized controlled trials [1, 3, 5, 12, 22] and are in accordance with the results of lately published meta-analysis [9, 21, 33, 37, 38].

The ROM of both groups was also not significantly different across the time. This result contradicts the one by Aggarwal et al. [1], where the mean ROM was greater in the MB group ( $p=0.01)$, but is reinforced by the results of two meta-analysis [9, 21], in which no differences in ROM were found, when comparing FB and MB TKA designs.

Patient's pain perception was assessed with the use of the KSS questionnaire. At baseline, there was a floor-effect, with the median of both groups situated at " 0 " points (severe pain) and the second percentile at "10" points (moderate continual pain). TKA reduced pain significantly. 
Table 4 Implant positioning and leg alignment data between the FB and $\mathrm{MB}$ groups

Values are mean $\pm \mathrm{SD}$

n.s. non-significant

${ }^{a}$ Deviation (degrees) from $90^{\circ}$

b Absolute differences (degrees) from the target alignment

Table 5 Relationship between implant positioning, leg alignment data and the clinical scores
Values are the results of the Pearson's product-moment correlations $(r)$

$* p<0.5$

\begin{tabular}{llll}
\hline Variables & FB & MB & Mean diff. \\
\hline Implant positioning (navigation data) $^{\mathrm{a}}$ & & & \\
Femoral angle coronal (FAC) $^{\mathrm{a}}$ & $0.8 \pm 0.7$ & $0.8 \pm 0.7$ & 0.04 (n.s.) \\
Femoral angle sagittal (FAS) $^{\mathrm{a}}$ & $0.9 \pm 0.6$ & $1.0 \pm 0.7$ & 0.05 (n.s.) \\
Tibial angle coronal (TAC) $^{\mathrm{a}}$ & $0.7 \pm 0.4$ & $0.7 \pm 0.5$ & 0.01 (n.s.) \\
Tibial angle sagittal (TAS) $^{\mathrm{a}}$ & $3.7 \pm 1.3$ & $3.9 \pm 0.9$ & 0.02 (n.s.) \\
Leg alignment (standing X-ray) $_{\text {Mechanical axis (pre-operatively) }}^{\mathrm{b}}$ & & & \\
Mechanical axis (post-operatively 1 year) $^{\mathrm{b}}$ & $2.8 \pm 3.9$ & $8.1 \pm 3.5$ & 0.1 (n.s.) \\
\hline
\end{tabular}

\begin{tabular}{|c|c|c|c|c|c|c|}
\hline Variables & FAC & FAS & TAC & TAS & MA-P & MA-1 Y \\
\hline KSS-Function 1 year & 0.04 & 0.13 & -0.05 & 0.14 & 0.03 & -0.06 \\
\hline KSS-Knee 1 year & 0.12 & 0.07 & 0.15 & 0.09 & 0.18 & -0.18 \\
\hline $\begin{array}{l}\text { Maximal Knee Flexion } \\
1 \text { year }\end{array}$ & 0.06 & $0.22 *$ & -0.09 & -0.11 & 0.04 & 0.01 \\
\hline \multicolumn{7}{|l|}{ Femoral angle coronal (FAC) } \\
\hline Femoral angle sagittal (FAS) & 0.08 & & & & & \\
\hline Tibial angle coronal (TAC) & -0.01 & -0.06 & & & & \\
\hline Tibial angle sagittal (TAS) & -0.15 & 0.03 & -0.17 & & & \\
\hline $\begin{array}{l}\text { Mechanical axis pre- } \\
\text { operatively (MA-P) }\end{array}$ & 0.07 & -0.04 & -0.09 & 0.17 & & \\
\hline $\begin{array}{l}\text { Mechanical axis } 1 \text { year (MA- } \\
1 \mathrm{Y})\end{array}$ & -0.15 & 0.07 & 0.21 & 0.09 & 0.10 & \\
\hline Mean \pm SD & $0.85 \pm 0.6$ & $0.99 \pm 0.6$ & $0.76 \pm 0.5$ & $3.8 \pm 1.1$ & $8.1 \pm 3.7$ & $2.0 \pm 1.5$ \\
\hline
\end{tabular}

At 1 and 4 years, there was a ceiling effect, with the median of both groups placed at 50 points (no pain) and the 1st percentile at 45 points (mild or occasional pain) (Fig. 2a). There were no statistically significant differences when comparing the median or the distribution of values in both groups, showing no advantage of the MB over the FB design in terms of better pain relief. Since the localization of the perceived pain was not discriminated in the present study, it is not possible to answer the question whether the MB design is more patella friendly than the FB design in terms of less anterior knee pain incidence. This may be one of the clinical advantages of the MB with its "self-alignment" of the tibial bearing. In the literature, there are contradictory findings on this matter. In a study by Breugam et al. [6], there were significantly more patients (18.9\%) experiencing anterior knee pain in the FB (posterior-stabilized) then in the MB group (4.3\%) 1 year after TKA. However, the same authors did not confirm their results 7.9 years after surgery [7]. In contrast, a meta-analysis [21] showed lower pain scores in the MB group (OR 0.66; $95 \%$ CI -0.60 to 0.26 ). Also in a retrospective study by Wyatt et al. [40], there were higher revision rates for resurfacing of the patella in the FB posterior-stabilized TKA than in MB designs, indicating that the implant design may have an influence on the patella-femoral biomechanics.
Computer-assisted TKA allows the surgeon to accurately control parameters related to the implant position and soft tissue balance. In a recent study [14], it was demonstrated that computer-assisted TKA resulted in fewer outliers in frontal leg alignment and tibial component positioning in comparison with conventionally performed TKA. The posterior tibial slope was also better achieved in the computer-assisted group. In the present study, the mean values of the assessed navigation parameters are very near zero, with small ranges and without significant differences in implant positioning when comparing both groups (Table 4). As expected, there were also no significant strong relationships between the implant positioning data and the clinical scores. This result reinforces the ones by Widmer et al. [39]. Also Ishii et al. [18] found no significant correlations between the condylar offset and the maximal knee flexion 1 year post-surgery.

One of the limitations of the present study is the fact that only the golden standard clinical scores were used to compare the groups. Retrospectively, it would have been interesting to have used performance-based standardized tests, like the "Timed Up and Go" or the "Stair Climbing Test" $[13,23,35]$, to assess and compare the patients in real-life tasks in a laboratory setting. The OXF is a selfreport questionnaire, and the KSS is based on both, patients self-report and assessor's perception. They are efficient and 
cost-effective but are they sensitive enough to discriminate functional changes? Patient's perceptions may not be discriminative enough as shown in a study by Thomsen et al. [36] on the magnitude of knee flexion after TKA, in which the high flexion TKA group achieved significantly higher knee flexion, however, no significant differences in patient's perceived outcomes were found when comparing the groups. A second limitation of the present study is the fact that patient's pain perception was assessed according to the KSS protocol without discrimination of pain localization. It would have beneficial to assess pain discrimination with the additional use of the anterior knee pain scale [20].

With the results of this study, the body of evidence supporting no superiority of MB over the FB designs in terms of better functional outcome scores, less pain or higher ROM grows. Further research comparing FB and MB designs should include performance-based measures beside self-reported questionnaires. Furthermore, the assessment of pain should discriminate the pain localization to enable researchers to answer the question whether MB designs are more patella friendly than FB.

\section{Conclusion}

In view of the 4-year results, there is no evidence to support the recommendation of one design over the other in terms of better clinical outcome scores, higher ROM or lower pain rates, since both groups achieved the same outcomes. Longterm follow-up results may be necessary, including survival rates. Further research comparing different TKA designs should also include standardized performance-based tests.

Acknowledgments The authors would like to thank Klaus-Ulrich Lemke for his help during the patient recruiting period.

Conflict of interest Prof. Dr. Lampe is consultant for B. Braun Aesculap. B. Braun Aesculap is sponsoring the research position of Mr. Marques at the Research Office of the Joint Replacement Center. Dr. Sufi-Siavach and Ms. Daniel have no financial relationships to disclose.

Ethical standard The research proposal was approved by the Medical Ethics Commission of the Federal State of Hamburg (File Number: \#2226). The clinical trial was registered under ClinicalTrials.gov (NCT00822640).

Open Access This article is distributed under the terms of the Creative Commons Attribution License which permits any use, distribution, and reproduction in any medium, provided the original author(s) and the source are credited.

\section{References}

1. Aggarwal AK, Agrawal A (2013) Mobile versus fixed-bearing total knee arthroplasty performed by a single surgeon: a 4- to 6.5- year randomized, prospective, controlled, double-blinded study. J Arthroplasty 28(10):1712-1716

2. Alentorn-Geli E, Leal-Blanquet J, Guirro P, Hinarejos P, Pelfort X, Puig-Verdie L (2013) Comparison of quality of life between elderly patients undergoing TKA. Orthopedics 36(4):e415-e419

3. Bailey O, Ferguson K, Crawfurd E, James P, May PA, Brown S, Blyth M, Leach WJ (2014) No clinical difference between fixedand mobile-bearing cruciate-retaining total knee arthroplasty: a prospective randomized study. Knee Surg Sports Traumatol Arthrosc. doi:10.1007/s00167-014-2877-9

4. Brandes M, Ringling M, Winter C, Hillmann A, Rosenbaum D (2011) Changes in physical activity and health-related quality of life during the first year after total knee arthroplasty. Arthritis Care Res (Hoboken) 63(3):328-334

5. Breeman S, Campbell MK, Dakin H, Fiddian N, Fitzpatrick R, Grant A, Gray A, Johnston L, MacLennan GS, Morris RW, Murray DW (2013) Five-year results of a randomised controlled trial comparing mobile and fixed bearings in total knee replacement. Bone Joint J 95-B(4):486-492

6. Breugem SJ, Sierevelt IN, Schafroth MU, Blankevoort L, Schaap GR, van Dijk CN (2008) Less anterior knee pain with a mobilebearing prosthesis compared with a fixed-bearing prosthesis. Clin Orthop Relat Res 466(8):1959-1965

7. Breugem SJ, van Ooij B, Haverkamp D, Sierevelt IN, van Dijk CN (2012) No difference in anterior knee pain between a fixed and a mobile posterior stabilized total knee arthroplasty after 7.9 years. Knee Surg Sports Traumatol Arthrosc 22(3):509-516

8. Bruyere O, Ethgen O, Neuprez A, Zegels B, Gillet P, Huskin JP, Reginster JY (2012) Health-related quality of life after total knee or hip replacement for osteoarthritis: a 7-year prospective study. Arch Orthop Trauma Surg 132(11):1583-1587

9. Cheng M, Chen D, Guo Y, Zhu C, Zhang X (2013) Comparison of fixed- and mobile-bearing total knee arthroplasty with a mean five-year follow-up: a meta-analysis. Exp Ther Med 6(1):45-51

10. Chiu KY, Ng TP, Tang WM, Lam P (2001) Bilateral total knee arthroplasty: one mobile-bearing and one fixed-bearing. J Orthop Surg (Hong Kong) 9(1):45-50

11. Dawson J, Fitzpatrick R, Murray D, Carr A (1998) Questionnaire on the perceptions of patients about total knee replacement. J Bone Joint Surg Br 80(1):63-69

12. Ferguson KB, Bailey O, Anthony I, James PJ, Stother IG, JGB M (2014) A prospective randomised study comparing rotating platform and fixed bearing total knee arthroplasty in a cruciate substituting design: outcomes at 2 year follow-up. Knee 21(1):151-155

13. Gandhi R, Tsvetkov D, Davey JR, Syed KA, Mahomed NN (2009) Relationship between self-reported and performancebased tests in a hip and knee joint replacement population. Clin Rheumatol 28(3):253-257

14. Gothesen O, Espehaug B, Havelin LI, Petursson G, Hallan G, Strom E, Dyrhovden G, Furnes O (2014) Functional outcome and alignment in computer-assisted and conventionally operated total knee replacements: a multicentre parallel-group randomised controlled trial. Bone Joint J 96-B(5):609-618

15. Hakki S, Saleh KJ, Potty AG, Bilotta V, Oliveira D (2013) Columbus navigated TKA system: clinical and radiological results at a minimum of 5 years with survivorship analysis. Orthopedics 36(3):e308-e318

16. Insall JN, Dorr LD, Scott RD, Scott WN (1989) Rationale of the knee society clinical rating system. Clin Orthop Relat Res 248:13-14

17. Iosifidis M, Iliopoulos E, Neofytou D, Sakorafas N, Andreou D, Alvanos D, Kyriakidis A (2014) The Rotaglide mobile-bearing total knee arthroplasty: no difference between cemented and hybrid implantation. Knee Surg Sports Traumatol Arthrosc. doi:10.1007/s00167-013-2829-9 
18. Ishii Y, Noguchi H, Takeda M, Sato J, Toyabe S (2013) Posterior condylar offset does not correlate with knee flexion after TKA. Clin Orthop Relat Res 471(9):2995-3001

19. Jones CA, Pohar S (2012) Health-related quality of life after total joint arthroplasty: a scoping review. Clin Geriatr Med 28(3):395-429

20. Kujala UM, Jaakkola LH, Koskinen SK, Taimela S, Hurme M, Nelimarkka O (1993) Scoring of patellofemoral disorders. Arthroscopy 9(2):159-163

21. Li YL, Wu Q, Ning GZ, Feng SQ, Wu QL, Li Y, Hao Y (2012) No difference in clinical outcome between fixed- and mobilebearing TKA: a meta-analysis. Knee Surg Sports Traumatol Arthrosc 22(3):565-575

22. Mahoney OM, Kinsey TL, D'Errico TJ, Shen J (2012) The John Insall Award: no functional advantage of a mobile bearing posterior stabilized TKA. Clin Orthop Relat Res 470(1):33-44

23. Mizner RL, Petterson SC, Clements KE, Zeni JA Jr, Irrgang JJ, Snyder-Mackler L (2011) Measuring functional improvement after total knee arthroplasty requires both performance-based and patient-report assessments: a longitudinal analysis of outcomes. J Arthroplasty 26(5):728-737

24. Mugnai R, Digennaro V, Ensini A, Leardini A, Catani F (2014) Can TKA design affect the clinical outcome? comparison between two guided-motion systems. Knee Surg Sports Traumatol Arthrosc 22(3):581-589

25. Norkin CC, White DJ (2009) Measurement of joint motion: a guide to goniometry, 4th edn. F. A Davis, Philadelphia

26. Nunez M, Lozano L, Nunez E, Segur JM, Sastre S, Macule F, Ortega R, Suso S (2009) Total knee replacement and healthrelated quality of life: factors influencing long-term outcomes. Arthritis Rheum 61(8):1062-1069

27. Papakostidou I, Dailiana ZH, Papapolychroniou T, Liaropoulos L, Zintzaras E, Karachalios TS, Malizos KN (2012) Factors affecting the quality of life after total knee arthroplasties: a prospective study. BMC Musculoskelet Disord 13:116

28. Parratte S, Pauly V, Aubaniac JM, Argenson JN (2012) No longterm difference between fixed and mobile medial unicompartmental arthroplasty. Clin Orthop Relat Res 470(1):61-68

29. Price AJ, Rees JL, Beard D, Juszczak E, Carter S, White S, de Steiger R, Dodd CA, Gibbons M, McLardy-Smith P, Goodfellow JW, Murray DW (2003) A mobile-bearing total knee prosthesis compared with a fixed-bearing prosthesis. A multicentre singleblind randomised controlled trial. $\mathrm{J}$ Bone Joint Surg $\mathrm{Br}$ 85(1):62-67

30. Ranawat CS, Flynn WF Jr, Saddler S, Hansraj KK, Maynard MJ (1993) Long-term results of the total condylar knee arthroplasty. A 15-year survivorship study. Clin Orthop Relat Res 286:94-102

31. Roh YW, Jang J, Choi WC, Lee JK, Chun SH, Lee S, Seong SC, Lee MC (2013) Preservation of the posterior cruciate ligament is not helpful in highly conforming mobile-bearing total knee arthroplasty: a randomized controlled study. Knee Surg Sports Traumatol Arthrosc 21(12):2850-2859

32. Sabouret P, Lavoie F, Cloutier JM (2013) Total knee replacement with retention of both cruciate ligaments: a 22-year follow-up study. Bone Joint J 95(7):917-922

33. Smith H, Jan M, Mahomed NN, Davey JR, Gandhi R (2011) Meta-analysis and systematic review of clinical outcomes comparing mobile bearing and fixed bearing total knee arthroplasty. J Arthroplasty 26(8):1205-1213

34. Stoner K, Jerabek SA, Tow S, Wright TM, Padgett DE (2013) Rotating-platform has no surface damage advantage over fixedbearing TKA. Clin Orthop Relat Res 471(1):76-85

35. Swinkels A, Allain TJ (2013) Physical performance tests, selfreported outcomes, and accidental falls before and after total knee arthroplasty: an exploratory study. Physiother Theory Pract 29(6):432-442

36. Thomsen MG, Husted H, Otte KS, Holm G, Troelsen A (2013) Do patients care about higher flexion in total knee arthroplasty? a randomized, controlled, double-blinded trial. BMC Musculoskelet Disord 14:127

37. van der Voort P, Pijls BG, Nouta KA, Valstar ER, Jacobs WC, Nelissen RG (2013) A systematic review and meta-regression of mobile-bearing versus fixed-bearing total knee replacement in 41 studies. Bone Joint J 95-B(9):1209-1216

38. Wen Y, Liu D, Huang Y, Li B (2011) A meta-analysis of the fixed-bearing and mobile-bearing prostheses in total knee arthroplasty. Arch Orthop Trauma Surg 131(10):1341-1350

39. Widmer BJ, Scholes CJ, Lustig S, Conrad L, Oussedik SI, Parker DA (2013) Intraoperative computer navigation parameters are poor predictors of function 1 year after total knee arthroplasty. J Arthroplasty 28(1):56-61

40. Wyatt MC, Frampton C, Horne JG, Devane P (2013) Mobileversus fixed-bearing modern total knee replacements- which is the more patella-friendly design? the 11-year New Zealand Joint Registry study. Bone Joint Res 2(7):129-131

41. Zeng Y, Shen B, Yang J, Zhou ZK, Kang PD, Pei FX (2013) Is there reduced polyethylene wear and longer survival when using a mobile-bearing design in total knee replacement? a meta-analysis of randomised and non-randomised controlled trials. Bone Joint J 95(8):1057-1063 